\title{
"Enlouquecer com": o caso Ferenczi e algumas questões para a psicanálise contemporânea
}

\author{
"To go crazy with": Ferenczi's case \\ and some questions for contemporary \\ psychoanalysis
}

\author{
Eugênio Canesin Dal Molin*1 \\ Thais Klein*2 \\ Isabella Silva Borghesi Dal Molin*3 \\ Nelson Ernesto Coelho Junior*4
}

A partir do "caso Ferenczi", como identificado em um texto de sua paciente/analista, Elizabeth Severn, o artigo apresenta e desenvolve três questões pertinentes à psicanálise contemporânea: uma crítica à ênfase na leitura diagnóstica, em especial quando normatizadora; a criação de espaços intersubjetivos em análise, e sua dimensão potencial; e a maneira como a "loucura", uma vez compartilhada, é psiquicamente mobilizadora e permite a emergência de conteúdos relevantes tanto para o paciente como para o analista. Discute-se se possibilidade de adotar uma posição não normativa frente aos elementos disruptivos do psiquismo do outro não seria, ao menos em parte, resultado da capacidade do analista em transitar por entre fragmentos de seu próprio psiquismo.

Palavras-chave: Ferenczi, Severn, psicanálise, loucura, contratransferência

\footnotetext{
*1,3 Centro Universitário Filadélfia - Unifil (Londrina, PR, Brasil).

*2 Centro Universitário Augusto Motta (Rio de Janeiro, RJ, Brasil).

*4 Universidade de São Paulo - USP (São Paulo, SP, Brasil).
} 
Em conferências proferidas recentemente, Jô Gondar (2017, 2019) e Felícia Knobloch (2019) apresentaram, cada uma à sua maneira, leituras interessantes e críticas sobre a "normatividade" que nós analistas adotaríamos, explícita ou implicitamente, ao pensar sobre o que seria o bom resultado de uma análise. As autoras salientavam a preocupação com certa visão sobre o tratamento que era, também, uma visão sobre o quanto de loucura - de fragmentação (Knobloch, 2019) e de compulsão (Gondar, 2017), em especial - no paciente acolhemos e damos reconhecimento no trabalho clínico, sem buscar, propriamente, uma integração estável. O pensamento inicial de que se tratava de uma falsa polêmica — uma vez que, imaginávamos, não aparentava grassar em nosso meio uma idealização normativa do psiquismo ou de sua adequação, conformidade e sanidade de caráter fixo e universal - revelou-se equivocado. ${ }^{1}$

As questões despertadas pelas conferências, e, mais tarde, por uma discussão aberta que propusemos sobre o tema, ${ }^{2}$ reafirmavam uma tenaz necessidade, mais ou menos reconhecida e clara, de indicar alguns pontos de chegada, ou valores fundamentais, capazes de ordenar o trabalho analítico e dar-lhe certa direção normativa a priori. Quando colocados em termos descritivos, os pontos de chegada ganhavam a tonalidade de prescrições que pareciam embotar a espontaneidade, muitas

\footnotetext{
${ }^{1}$ No campo da psicanálise com crianças, Sigal (2018) mostra preocupação semelhante e levanta uma série de hipóteses sobre os aspectos contemporâneos desse ímpeto normatizador, que pode atingir também o psicanalista, fazendo com que compactue, por exemplo, com uma hipermedicalização da infância.

${ }^{2}$ No II Encontro do Grupo Brasileiro de Pesquisas Sándor Ferenczi, realizado na PUC-Rio em novembro de 2019, propusemos (Dal Molin, 2019) uma "roda de conversa" (uma discussão com a participação de mais de vinte psicanalistas) sobre o estatuto da loucura em nosso meio a partir do caso Ferenczi.
} 


\section{ARTIGOS}

vezes vicejante, de algumas análises. Quando adotados marcadores muito gerais (como a vida ou a verdade, por exemplo), os argumentos terminavam por implicar o risco de que, numa situação clínica singular, o analista se percebesse partidário inflexível de determinada hierarquia de valores frente a um paciente que poderia buscar, repetidamente, colocar-se contrário a tal hierarquização.

Caso a colocação do problema nesses termos traga ao leitor a sensação de que a análise se transforma num campo minado de incertezas, e que seu aspecto desalentador cause a impressão de tratar-se de um trabalho da ordem do impossível, sem balizas claras quanto à direção do tratamento, gostaríamos de dar duas notícias. A primeira, e talvez desnecessária, é que sim, o impossível faz parte do negócio (Freud, 1937/2019). A segunda é que as coisas podem piorar.

Este artigo é o resultado de um exercício coletivo realizado sobre uma base comum. Demo-nos um campo de jogo - um trecho da pesquisa de um dos autores (Dal Molin, 2018) — e, em encontros com diferentes conformações, fizemos o material mover-se em algumas direções conhecidas e em outras que, antes de iniciado o exercício, eram-nos desconhecidas. Uma vez acomodados nesses espaços de jogo, procuramos inverter o ângulo da investigação indicado por Gondar (2017; 2019) e Knobloch (2019): nos perguntamos se os aspectos não integrados, fragmentados do analista (sua loucura) não poderiam ser responsáveis por uma maior disposição para reconhecer e sustentar aquilo que, na vida psíquica do paciente, também se mostra fragmentado, avesso à normatização e às variadas tentativas de circunscrição. Em outras palavras, nossa questão de partida pode ser colocada da seguinte forma: a aceitação e a capacidade para adotar uma posição ética não normativa frente aos elementos disruptivos do psiquismo do outro não seria, ao menos em parte, resultado da capacidade do analista em transitar por entre, e consequentemente expressar, com maior ou menor sucesso, partes fragmentadas e cindidas de seu próprio psiquismo? ${ }^{3}$

${ }^{3}$ Também levantamos outras duas questões: como a comunidade analítica trataria aqueles entre seus membros que são capazes de realizar tal trânsito? Leia-se, quanto de loucura admitimos em nossos colegas? E como lidamos com a loucura de autores cujas obras, muitas vezes, servem-nos bem no trabalho clínico? É evidente que um encaminhamento para estas perguntas não poderá ser realizado neste texto; e é bastante provável que os próprios analistas encontrem dificuldades em elaborar discursivamente eventuais respostas para estas perguntas - colocá-las, todavia, expõe um campo aberto que se configura como lastro dos nossos questionamentos. 
Nossa proposta diante desse questionamento é que, a partir de um episódio célebre, a "análise mútua" entre Sándor Ferenczi e Elizabeth Severn, possamos fazer trabalharem essas ideias no sentido de uma concepção mais verossímil e não idealizada sobre o lugar da loucura do (e no) analista.

\section{O caso Ferenczi}

No limite de suas experiências com a técnica, Ferenczi aceitou a proposta de uma paciente norte-americana, Elizabeth Severn, que fora vítima de uma série de violências e se apresentava como terapeuta, embora sem formação, para que ela também o analisasse enquanto era analisada por ele. Concordaram com a chamada "análise mútua" (Fortune, 1993, 1996; Kahtuni \& Sanches, 2009; Bonomi, 2018; Rachman, 2018). As dificuldades, problemas e consequências dessa experiência podem ser acompanhadas na leitura do Diário clínico mantido por Ferenczi (1932/1988) em 1932. Na introdução escrita para uma reedição do livro The Discovery of the Self, de Elizabeth Severn (2017), Peter L. Rudnytsky (2017) identifica e discute algumas passagens, sobretudo o capítulo 5, em que Severn apresenta o que seria, em sua (de Peter) leitura, o caso de Ferenczi. Severn (2017) escreve sobre um paciente

de posição moral e intelectual inusuais, com uma perspectiva balanceada sobre a vida e nítida serenidade de modos. Sofria de vários sintomas físicos que atribuía a causas físicas, ajudado por vários diagnósticos médicos que confirmaram seus medos. Essas doenças eram crônicas com um prognóstico desfavorável e o homem estava em um estado de constante depressão em relação à sua saúde. A análise logo revelou um definitivo quadro clínico psicológico suficiente para explicar seu estado de deterioração física. A análise não revelou, entretanto, a não ser após considerável trabalho, uma psicose claramente delineada. (p. 96)

E continua:

O paciente não era a equilibrada, bem ajustada pessoa que ele, e outros, haviam imaginado.

Essa condição foi naturalmente percebida por mim antes do paciente e só foi reconhecida por ele depois de ser involuntariamente atuada... Ele subitamente falou-me um dia sobre a peça $O$ pai, de Strindberg, e tornou-se quase imediatamente ele mesmo o filho insano. Ele desmoronou e perguntou 


\section{ARTIGOS}

com lágrimas nos olhos se eu algumas vezes pensaria nele com amabilidade depois que fosse internado em um manicômio. Ele evidentemente esperava ser internado naquele momento, acrescentando como últimas palavras, com terrível pathos, "E gostamos, quando a camisa de força deve ser posta em nós, que isto deva ser feito por nossa mãe". Imediatamente vi assim que o paciente estava reexperimentando um trauma severo no qual havia esperado que sua mãe se livrasse dele como louco, mas foi só no dia seguinte que se deu conta da importância desse impressionante incidente. Já sabíamos algo sobre essa história, sobre sua mãe ser uma mulher raivosa, histérica, frequentemente repreendendo e ameaçando seu filho, e especialmente por certo evento no qual ela o tratou com tal dureza e injúria que fez com que ele se sentisse completamente louco e marcado como um criminoso. (Severn, 2017, pp. 96-97)

A autora norte-americana afirma que "a inesperada reprodução na análise de uma parte da dolorosa cena permitiu a ele [Ferenczi] reconhecer essa insanidade traumaticamente-causada pela primeira vez como um fato em si mesmo" (Severn, 2017, p. 97; grifo nosso), o que teria dado início à dissolução do quadro. De acordo com Rudnytsky (2017), provavelmente a cena a que se refere Severn ocorreu quando Ferenczi tinha três anos, e fora relatado a Freud anos antes, numa carta de 26 de dezembro de 1912 (Brabant, Falzeder, \& Giampieri-Deutsch, 1993)

$\mathrm{Na}$ carta, Ferenczi defende a necessidade da análise dos analistas e quer dar início à sua própria, contrapondo-se a Jung, que não queria submeter-se a uma análise. No que chama de "gratis analysis" (Brabant, Falzeder \& Giampieri-Deutsch, 1993, p. 455) com Freud, o húngaro relata dois sonhos e apresenta em detalhe suas associações sobre um deles. Não é todo o conteúdo manifesto e todas as associações que nos interessam no momento, mas as partes que, como sugere Rudnytsky (2017), teriam reaparecido no experimento da análise mútua.

Ferenczi escreve a Freud, em 1912, que não gostaria de tratar sua amante Frau Gisela, da mesma maneira sádica que uma vez tratou sua irmã mais nova, "Gisela, ${ }^{4}$ com quem fui pego pela cozinheira, aos três anos aproximadamente (talvez antes) em toques mútuos e (após ter sido contado [reported] a minha mãe?) ameaçado com uma faca de cozinha (obviamente uma ameaça de castração)" (Brabant, Falzeder \& Giampieri-Deutsch, 1993, p. 452).

${ }^{4}$ Cuja grafia do nome, na verdade, é Gizella. Ao mudar a grafia do nome, Ferenczi parece estar destacando como a associação entre ambas também se mostra na homofonia dos nomes. 
Na mesma carta, Ferenczi faz referência a outro episódio de natureza sexual que experimentou na infância, com um menino mais velho, e conta uma série de particularidades de sua vida sexual adulta. Para nossos propósitos, é um trecho pertinente à relação de Ferenczi com sua mãe que chama a atenção. Lemos, "quando menino eu tinha uma colossal un. . . . . . . 5 ira contra minha mãe, que era muito severa comigo; a fantasia de assassinato (da qual não me lembro com certeza) foi imediatamente voltada contra minha própria pessoa" (Brabant, Falzeder \& Giampieri-Deutsch, 1993, p. 542). As associações continuam:

A palavra [...] (um adjetivo com o qual queria expressar minha inabilidade, meu estar ligado [bound], minha vontade inibida) não vem à minha mente em alemão! Em húngaro a palavra é "tehetetlen", que ao mesmo tempo também significa impotente. Então: "minha ira impotente contra minha mãe. (p. 452; grifo nosso)

A palavra Tehetetlen também pode ser traduzida por "desamparado" e, seja qual for a abertura semântica que busquemos — se idêntica ou mais ampla que a encontrada por Ferenczi ao relatar seu sonho a Freud - o que vemos é o ato incestuoso descoberto, a ameaça de castração experimentada como uma ameaça mortífera e uma aguda hostilidade do então menino contra sua mãe, que não pôde ganhar forma em ato ou ser expressada, voltando-se, por fim, contra a própria criança impotente e desamparada. Retornaremos a esse ponto em breve; no momento, é oportuno continuar acompanhando o relato do caso como feito por Elizabeth Severn.

A norte-americana acrescenta que outro trauma, relacionado, mas não igual ao experimentado com a mãe, existia na história do paciente: "um ataque inescrupuloso de uma pessoa adulta às sensibilidades da criança" (Severn, 2017, p. 97), o que teria demolido sua integridade psíquica. O evento envolveu uma ama, quando o paciente tinha seis anos, utilizando-o para satisfazer os próprios desejos. Lemos:

Outra empregada, tendo sido uma testemunha parcial do ocorrido, contou imediatamente para a mãe do menino, após ter ela mesma o ameaçado com uma violenta punição. A reação de sua mãe foi ainda mais severa e foi direcionada principalmente para o menino, como se ele fosse o culpado, e de um tipo indizível. Por sua condenação violenta ela o fez sentir-se o pior dos pecadores e completamente alienado de seu amor e compreensão. Ele curvou-se ao inevitável, mas estava quebrado. (p. 99)

${ }^{5}$ Espaço pontilhado deixado pelo autor. 


\section{ARTIGOS}

Durante a análise, Severn identifica, numa primeira camada, o amargor, a raiva e a agressividade do paciente encobertos por candura; aponta também a existência de uma segunda camada, em que se encontrava "um homem com terror de todas as mulheres, sentindo igualmente raiva e paixão" (p. 99). Uma terceira camada, mais profunda, revelava

O choque ou psicose em que estava contido o sofrimento agudo, a perda da confiança sexual, e o ódio da injustiça que aguentou, em proporções iguais. Tudo isso fragmentado em pequenos pedaços, muito convertido em sintomas físicos, e nada disso reconhecível pelo que era, uma reprimida insanidade de tipo virulento. [...] Ele [o paciente] eliminou todo o assunto com seus (para ele) misteriosamente inexplicáveis elementos, e sua própria fúria, de sua consciência. (p. 99; grifos nossos)

Esse movimento compensatório, argumenta a autora, teria permitido que o menino se tornasse um homem inteligente, prestativo e equilibrado, ao custo de sua saúde e felicidade.

Cremos ter o bastante para ao menos três comentários articulados às nossas perguntas iniciais: um relacionado à questão diagnóstica, outro ao espaço intersubjetivo criado pela dupla Ferenczi/Severn e, um último, que diz respeito à maneira como a "loucura", uma vez compartilhada, é psiquicamente mobilizadora para ambos os envolvidos.

\section{Que psicose?}

O primeiro desses comentários, de problematização diagnóstica, é introduzido pelo próprio Rudnytsky (2017), para quem, embora a "imputação de uma 'psicose' a Ferenczi possa parecer extrema, ela é corroborada por sua admissão" (p. 10). Tal admissão foi feita no Diário clínico, na entrada do dia 19 de julho de 1932, onde lemos o húngaro afirmar que a visão psicanalítica sobre seu "próprio vazio emocional, que estava envolto por supercompensação (recalcado - inconsciente - psicose) levou a um autodiagnóstico de esquizofrenia" (Ferenczi, 1932/1988, p. 160). O diagnóstico de ambos, Severn e Ferenczi, podemos contra-argumentar, soa

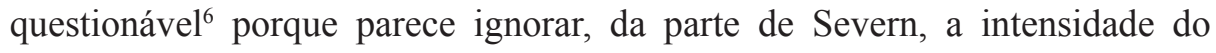

${ }^{6}$ Como se sabe, a atribuição de uma psicose a Ferenczi serviu a vários propósitos. Para uma síntese crítica da história desse diagnóstico, conferir Bonomi (1998). 
movimento transferencial do húngaro - que, afinal, tornou-se ele mesmo paciente de sua paciente - e, da parte de Ferenczi, porque embora reconheça a intensidade de sua contratransferência transformada em transferência dirigida a Severn, não se demora no fato de que os afetos e seu estado mental durante as sessões reproduzem sem contraste aqueles que experimentou frente à sua mãe. Esse é, a nosso ver, um impasse manifesto do experimento da análise mútua que pode ecoar — com menos estridência, é verdade — de forma latente no trabalho de outras duplas analíticas.

Desde o início da experiência da análise mútua, Ferenczi já anotara em seu Diário, sob a data de 24 de fevereiro de 1932: "Para usar o modo de expressão de R.N.", sigla pela qual identificava Severn, "em R.N. encontro novamente minha mãe, isto é, a real, que era dura e enérgica e de quem eu tinha medo" (1932/1988, p. 45; grifo nosso). Na reprodução da cena traumática que se permite com Severn, Ferenczi e sua analista/paciente parecem ter eliminado a necessidade de um "contraste entre o presente e o insuportável passado traumatogênico" (Ferenczi, 1933/2002d, p. 160) repetido em análise. A "realidade clínica" (Coelho Junior, 1995) coloca o húngaro frente a alguém com uma personalidade que lhe parece idêntica 228 à de sua mãe, e aproxima-se perigosamente da realidade traumática experimentada anteriormente. O resultado é julgar-se louco, como quando estava sob o domínio da mãe. Voltaremos à questão pertinente à realidade clínica em breve.

Curiosamente, entretanto, a posição de Ferenczi e Severn sobre a emergência desse tipo de material em uma análise não condiz plenamente com uma nomenclatura diagnóstica que utilizam para o caso: "esquizofrenia". Já o uso das expressões "reprimida insanidade", "choque ou psicose" e "insanidade traumaticamente-causada" aponta noutra direção mais frutífera.

Resumidamente, na fase final de sua obra, Ferenczi defendia que o trauma psíquico aciona defesas mais primitivas que o recalque, ideia que encontrava ressonância positiva em Freud (Dal Molin, 2016). ${ }^{7}$ Todo choque, de acordo com o autor húngaro, tem como efeito inicial uma "psicose transitória, ou seja, um afastamento da realidade" (Ferenczi, 1930/2002b, p. 121; grifo nosso). Sob a influência do choque, argumenta Ferenczi

\footnotetext{
${ }^{7}$ Para uma perspectiva mais detalhada ver: Cf. Dal Molin (2016, 2017); e Mello, Féres-
} -Carneiro e Magalhães (2019). 
(1930/2002b), ocorre uma "clivagem psicótica" (p. 121) que isola uma parte da personalidade. No caso de choques numerosos, o que encontramos é uma "fragmentação" do psiquismo (Ferenczi, 1933/2002d, p. 165), que consiste em um recurso útil, posto que engendra uma espécie de divisão de tropas: um pelotão é sacrificado em prol da possibilidade de fuga e da subsistência dos demais. Mas isso não é, propriamente, idêntico ao que se encontra na psicose, em especial na esquizofrenia.

Como observa Verztman (2002), o "empobrecimento do eu que se segue ao trauma é de ordem diversa do estreitamento subjetivo próprio às psicoses esquizofrênicas" (p. 68). A clivagem posterior ao trauma, na leitura de Ferenczi (1933/2002d), não gera um fechamento, mas um movimento eloquente de abertura: a identificação com o agressor. Essa noção é apresentada algumas vezes pelo autor. No contexto do modelo clínico-teórico, que tem como paradigma as situações de violência, em especial as de natureza sexual, Ferenczi escreve no Diário clínico (1932/1988):

É como se a psique, cuja única função é reduzir tensões emocionais e evitar a dor, no momento da morte de sua própria pessoa, automaticamente alterasse suas funções de aliviar a dor para as dores, tensões, e paixão do agressor, a única pessoa com sentimentos, isto é, se identificasse com elas. [...] Logo, não sinto a dor infringida sobre mim porque não existo. Por outro lado, sinto a gratificação prazerosa do agressor, que ainda sou capaz de perceber. (p. 104)

Pouco depois, ainda no Diário clínico, na entrada de 27 de julho de 1932, Ferenczi volta a organizar a ideia de uma forma descritiva:

É possível que, a cada choque esmagador, uma tentativa inicial de defesa agressiva, aloplástica seja efetuada, e somente quando confrontado com a completa percepção da própria impotência e desamparo absolutos alguém se submete inteiramente ao agressor ou mesmo identifica-se com ele. (p. 176)

Em “Confusão de línguas” (1933/2002d), a ideia volta a ser trabalhada. Lemos que a angústia causada pelo trauma, em seu ápice

Compele [as crianças] a subordinarem-se como autômatos à vontade do agressor, a adivinhar cada um de seus desejos e a gratificá-los; completamente abstraidos de si mesmos eles identificam-se com o agressor. Através da identificação, ou digamos, introjeção do agressor, ele desaparece como parte da realidade externa, e torna-se intra- ao invés de extra-psíquico; o intra-psíquico é então sujeito, em um estado de sonho como em transe traumático, ao processo primário. (p. 162; grifos do autor) 
Ora, em todas essas passagens, ${ }^{8}$ a identificação com o agressor é paralela, como dissemos, à clivagem, intensificando-a; e, além disso, contempla um movimento final, posterior a tentativas de defesa aloplástica, de hipersensibilidade e adaptação ao meio experimentado como hostil. É como se o exército derrotado, e que teve parte de seus homens sacrificada, se decidisse estrategicamente a viver disfarçado, adotando a insígnia e as cores do oponente, e a tornar-se mais leal, atento e disponível do que a própria tropa vitoriosa. Voltando ao caso, poderíamos dizer que uma aparente psicose pode, e muitas vezes é, uma reação autoplástica, adaptativa eficaz, contra um ambiente hostil e ameaçador.

Cabe notar ainda que, de acordo com Ferenczi (1930/2008b, p. 120), toda neurose contém um elemento traumático original - leia-se, de conflito entre o indivíduo e o meio (Dal Molin, 2016; Dal Molin, Coelho \& Cromberg, 2019) - de modo que um aprofundamento da análise, mesmo a de pacientes neuróticos, terminaria por revelar um substrato traumático, de choque seguido de clivagem.

A posição de Severn quanto a este assunto é similar. Antes mesmo de aproximar-se de Ferenczi, ela defendia que "toda neurose continha uma psicose (isto é, que todas desordens nervosas sérias têm algum grau de insanidade de fundo)" (Severn, 2017, p. 86). Se analisarmos um neurótico passando pelas camadas mais superficiais, escreve, na mesma direção de seu analista húngaro, "chega-se naquele estranho mundo chamado irrealidade, que é, para quem o possui, mais real que a "realidade" (Severn, 2017, p. 87). O encontro com Ferenczi parece ter contribuído para o desenvolvimento dessas ideias, permitindo conectá-las com a noção de trauma, a ponto de Severn falar em "níveis psicóticos" do psiquismo ao redor de uma experiência de choque severo. ${ }^{9}$ Em suas palavras,

Todo o modo de ser do paciente mostra uma tensão, intensidade e desorientação, e a devastação de um dano psíquico severo de algum tipo torna-se muito visível. Pode-se saber, assim, que se está muito perto, ou que se atingiu o ponto, do trauma original - que ao menos seus traços foram descobertos. (p. 91)

${ }^{8}$ Para uma discussão detalhada e exemplificada dessa noção ver: Dal Molin $(2016$; 2018).

${ }^{9}$ Ideia que aponta numa direção mais tarde explorada profundamente por Bion (1957/1984), quando escreve, por exemplo, que no neurótico grave "há uma personalidade psicótica escondida pela neurose, assim como a personalidade neurótica é ocultada pela psicose no psicótico” (p. 63). 


\section{ARTIGOS}

Ambos os autores, como se vê, estão debruçados sobre a ideia de que o trauma e as defesas por ele acionadas subsistem mesmo nos casos de neurose. Mais do que isso, parecem dar à clivagem, à psicose e à insanidade uma existência sob as barbas da neurose. Não estamos, nesse âmbito, muito afastados da posição também adotada por Freud (1937/2019), para quem o Eu normal seria uma "ficção ideal" (p. 300) ${ }^{10}$ :

Cada indivíduo é apenas medianamente normal, seu Eu se aproxima daquele do psicótico nesse ou naquele ponto, em extensão maior ou menor, e o grau de distanciamento de um extremo da série e de aproximação ao outro será, para nós, provisoriamente, uma medida dessa 'alteração do Eu', tão imprecisamente definida. (p. 300)

Parte do processo analítico, quando adotamos tal direção de leitura, adquire o objetivo de acessar e dar vazão a esse nível mais entranhado da vida psíquica, mesmo quando não é ele que domina completamente, e a maior parte do tempo, o modo de ser do paciente. Em outras palavras: a matriz clínica (Mezan, 2014) que parece dar luz à dimensão do trabalho analítico enfatizado por Ferenczi e Severn não está, propriamente, circunscrita a uma categoria diagnóstica, mas a certa ordem de experiências (traumas) em torno das quais o psiquismo se defenderia de forma aguda. Trata-se, é possível dizer, de um foco maior nos processos psíquicos, fazendo com que ganhem expressão, e menos nas estruturas, já formadas e estáveis, que os organizam posteriormente.

\section{Espaços de jogo e realidade clínica}

O segundo comentário que o caso desperta nos remete à pretensão de Ferenczi em vislumbrar a possibilidade de produzir uma quarta ferida

${ }^{10}$ Pode-se dizer que a noção de normalidade na obra de Freud varia, ainda que não haja uma discussão mais específica, talvez o texto que mais se aproxime diretamente deste problema seja "Psicopatologia da vida cotidiana" (Freud, 1901/1977). É justamente neste que se pode entrever com mais clareza certa concepção de normalidade e patologia destacada ao menos na primeira teoria pulsional, calcada em uma espécie de continuum entre o normal e o patológico e na busca pela homeostase - ora, não por acaso, esses aspectos remetem à influência indireta de Claude Bernard, cuja obra marcou o pensamento de Breuer. No entanto, a partir de 1920, algumas questões são colocadas, principalmente em relação à homeostase, fato que complexifica as noções de normal e patológico, extrapolando o escopo deste escrito. 
narcísica na humanidade (depois de Copérnico, Darwin e Freud), ao mostrar que não somos tão autônomos quanto desejaríamos em relação ao universo (Sabourin, 1988). A análise mútua implica uma problemática que, a nosso ver, permeia justamente as fronteiras entre o analista e o analisando, e suas respectivas loucuras.

Como se sabe, quase duas décadas após o experimento ferencziano, Loewald (1951/1980) resgatou algumas ideias de Paul Federn (1953) que insistiam na proposição de que os fenômenos da esquizofrenia se relacionam mais à perda dos limites do ego (e, portanto, a um ganho de realidade) do que a uma defesa diante da realidade, isto é, uma consequente perda de realidade. Nessa concepção, aparentada ao que vemos Ferenczi (1909/2011) escrever sobre a introjeção — em que introjetar não é "colocar para dentro", mas aumentar o eu de modo a abarcar os objetos — a realidade muda regressivamente seu caráter de tal forma que os limites entre ego e realidade se tornam fluidos. Partindo das ideias de Federn, Loewald (1951/1980) refere-se à transferência na esquizofrenia como um nível de relacionamento com o outro - diferente de uma relação objetal - muito próximo do narcisismo primário e dos sentimentos mágicos de identidade e influência 232 mútua. E acrescenta: “a extrema sensitividade, o 'sexto sentido' que muitas pessoas esquizoides têm com relação a outras pessoas e a qualidade empática de seus relacionamentos devem-se a uma integração ego-realidade mais fluída e menos diferenciada, semelhante aos estágios iniciais" (p. 19).

Muito embora a discussão sobre o tipo de loucura engendrada no âmbito da análise mútua esteja longe de alcançar um consenso (e, como vimos, não parece que a leitura diagnóstica é capaz de acrescentar muito aqui), a experiência, somada aos comentários de Loewald (1951/1980), quando tomados de forma ampla, parecem exigir justamente que pensemos a clínica psicanalítica em termos das realidades que a atravessam. Nesse sentido, a noção de uma realidade clínica (construída na situação analítica por analisando e analista) pode ser entendida como uma realidade que não é única, nem tampouco homogênea. Cada situação clínica é potencialmente criadora de uma realidade singular. A partir desta perspectiva é possível retirar do plano do trabalho clínico — e talvez também do que está para além dele — a ideia de que existe uma única e verdadeira realidade. As realidades clínicas não se repetem, propriamente, mas são compostas de diferentes e múltiplas realidades, sempre em movimento e em transformação (Coelho Junior, 2015).

As formas de ligação entre a realidade psíquica e a realidade material ou externa, tanto para o analista como para o analisando, estão longe de serem 


\section{ARTIGOS}

previsíveis e controláveis. Mas isto não quer dizer que as realidades sejam conjuntos preexistentes à situação clínica e, portanto, impossíveis de serem transformadas. A realidade clínica, parece-nos, é propriamente a realidade transferencial/contratransferencial. Com isso, indicamos que as noções de realidade externa e realidade psíquica, em si, são insuficientes para dar conta, ou mesmo para nomear, a realidade própria ao contexto terapêutico, a realidade marcada pela transferência, pela relação terapêutica e pelas expressões do inconsciente. Ao pensarmos sobre o experimento da análise mútua, portanto, seria mais indicado tomá-lo enquanto a cocriação, por Ferenczi e Severn, de uma realidade compartilhada que é, simultaneamente, oriunda das realidades psíquicas dos dois participantes, do atravessamento dessas realidades - e do que ele é capaz de gerar —, e, também, da natureza do espaço lúdico que montaram juntos.

Neste contexto, é interessante notar que Green (1990) assinala como um dos fatores responsáveis pela consolidação de um terceiro momento ${ }^{11}$ na história da psicanálise a tomada em consideração da realidade do analista na situação analítica. Nas suas palavras: "da mesma forma que a visão do mundo exterior do paciente depende da sua realidade psíquica, a nossa visão de sua realidade psíquica depende de nossa própria realidade psíquica" (p. 77). Esta reconfiguração consiste, sobretudo, na tomada em consideração do papel dos analistas na instalação da situação analítica e no desenvolvimento da análise. Trata-se do deslocamento de uma posição que concebia o outro (o paciente) como algo a ser conhecido (que pode ser circunscrita pela pergunta: "como se conhece o outro?"12), para a possibilidade de questionar a entrada em

${ }^{11}$ Grosso modo, os momentos discutidos por Green (1990) podem ser caracterizados por três deslocamentos. No primeiro deles, a teoria analítica calca-se na realidade histórica do paciente movimento claramente marcado pelo modelo freudiano caracterizado sobretudo pela descoberta do inconsciente e da transferência. $\mathrm{O}$ analista, enquanto receptáculo passivo da transferência, estará ancorado em uma função interpretativa exercida diante das representações transferidas e repetidas na sua figura. Um segundo momento diz respeito ao interesse deslocado em direção às relações de objeto abordadas de maneiras bastante distintas por autores tais como: Melanie Klein, Fairbain, Balint, Spitz, dentre outros - abrindo espaço para as primeiras discussões sobre a contratransferência. Já o terceiro movimento comporta outra dimensão da contratransferência na medida em que considera e dá destaque ao funcionamento mental do analisando e do analista, bem como e, principalmente, às questões relativas a uma terceira dimensão entre o analista e o analisando.

12 Esta discussão pode ser articulada a uma forma de caracterizar uma questão que marca, sobretudo, a modernidade chamada "o problema de outras mentes". 
contato com o outro - posição esta que implica considerar diversos graus da intersubjetividade. Ora, não seria a experiência da análise mútua e a consequente discussão sobre a loucura nos dois polos um impulsionador desta perspectiva?

Consideramos que o caso exposto acima se configura como um eixo central para a psicanálise contemporânea, mais especificamente, no que concerne às posições da realidade do analista e do analisando. A hipótese discutida por Green (1990), por exemplo, afirma que após Ferenczi, Winnicott leva adiante a consolidação do terceiro momento da história da psicanálise principalmente devido à sua preocupação em relação a uma "terceira zona de vida humana, que não está dentro do indivíduo, nem fora" (Winnicott, 1971/2007, p. 146). Em Playing and reality, Winnicott (1971/2007) afirma:

A psicoterapia acontece na sobreposição de duas áreas do brincar: a do paciente e a do analista. A psicoterapia envolve duas pessoas brincando juntas. O corolário disso é que, onde a brincadeira não é possível, o trabalho do analista é direcionado para trazer o paciente de um estado em que não é capaz de brincar a um estado em que é capaz de brincar. (p. 51)

No mesmo livro, pouco depois, a mesma ideia é defendida com alguns acréscimos:

O princípio geral que me parece válido é que a psicoterapia é feita na sobreposição de duas áreas do brincar, a do paciente e a terapeuta. Se o terapeuta não consegue brincar, ele não é adequado para o trabalho. Se o paciente não consegue brincar, então algo precisa ser feito para permitir que o paciente torne-se capaz de brincar, depois do que a psicoterapia pode começar. A razão pela qual o brincar é essencial é que é no brincar que o paciente está sendo criativo. (p. 72)

A noção de espaço potencial é delineada como um caminho possível para dar um destino a esses questionamentos. Seguindo as indicações de Coelho Junior (2015), essa noção permite que se possa levar em consideração três planos da realidade e não apenas dois - realidade material e realidade psíquica - frequentemente postos em oposição. O espaço potencial implica a possibilidade de experimentação da não integração, isto é, de limiares não completamente traçados entre o eu e o mundo - a atualização de potencialidades, nesse contexto, está articulada à experimentação de um terceiro espaço nem subjetivo, nem objetivo.

Abre-se caminho para outra perspectiva que necessariamente implica pensar a situação analítica não somente a partir de um (paciente) ou dois 
(analista e paciente), mas em torno do que se convencionou chamar de configurações da terceiridade (Coelho Junior, 2015). Isto é, de diferentes formas de conceber um terceiro elemento. ${ }^{13} \mathrm{Na}$ concepção de Green (1990), trata-se da passagem da análise do conteúdo à análise do continente para a análise do enquadre. ${ }^{14}$ A partir de uma discussão em torno de configurações da terceiridade, o problema deixa de estar concentrado no conhecimento do outro ou do mundo, para levar em consideração a experiência do próprio analista quando em contato com o outro - não seria possível privilegiar, desta perspectiva, a via do conhecimento de um dos lados. ${ }^{15}$

\section{"Enlouquecer com"}

O terceiro e último comentário que o caso desperta é diretamente resultado do trabalho de acesso ao trauma: uma tarefa central da análise, em alguns casos, torna-se propiciar a remontagem de aspectos da cena de batalha original (do conflito primário com o meio), e facilitar, através da criação de um espaço potencial - que é ele próprio o engendramento de uma realidade aberta e instável —, sua reencenação em termos menos desfavoráveis, de preferência com uma saída diferente daquela adotada quando da experiência original.

${ }^{13}$ Seguindo as indicações de Coelho Junior (2015), alguns dos principais exemplos das configurações de terceiridade ao longo da história da psicanálise são: em Freud a partir do Édipo, o terceiro na teoria lacaniana ligado ao nome do pai, o terceiro para Melanie Klein como posição depressiva, o espaço potencial de Winnicott, a noção de terceiro analítico de Ogden, de enquadre de Green, dentre outros.

${ }^{14}$ É preciso salientar que, a partir desse momento, a noção de enquadre passa a ser fundamental e, articulada aos conceitos de transferência e contratransferência, compõe um esquema terciário do processo analítico. $\mathrm{O}$ enquadre é um conceito tanto epistemológico quanto técnico, uma vez que diz respeito às condições de possibilidade para a constituição do objeto analítico, do seu recorte teórico e da sua transformação prática. Green (1990) afirma que em uma análise clássica (geralmente articulada à neurose), o enquadre se torna um elemento silencioso. Já no contexto de outros tipos de configurações psíquicas, o enquadre faz sentir a sua presença através, principalmente, da sensação de que algo se passa contra ele.

${ }^{15}$ Seria possível vincular esta perspectiva à discussão de diferentes psicanalistas contemporâneos tais como Green, Ogden, dentre outros. 
Essa reencenação só poderia ocorrer caso o paciente se permita, junto do analista, um movimento regressivo embebido pela confiança. Mas a confiança não é um produto inerente à análise. Em Ferenczi (1933/2002d), por exemplo, ela aparece como consequência de uma atitude do analista que mantém certa tensão receptiva, necessariamente autêntica, permeável à crítica e ao reconhecimento sincero dos próprios erros. E não plenamente consciente. Como escreve Coelho Junior (2004), encontramos no húngaro, de modo explícito desde sua publicação conjunta com Rank, em 1924, uma definição do trabalho analítico que "Recusa o primado da comunicação de ego a ego, a partir de representações, e afirma o primado de processos identificatórios apoiados em um fator emocional" (p. 81). No âmbito dessa compreensão, as "convicções, em termos da experiência analítica, não são conquistas intelectuais, mas sim conhecimentos que devem ser atribuídos à concordância entre uma parte da realidade e a vivência afetiva" (p. 81).

Se está aberta a possibilidade de articulação entre analista e analisando - em termos de processos identificatórios apoiados no que se convencionou chamar de confiança - aquilo que hipoteticamente pertence ao analista pode, e mesmo deve, em alguns casos, entrar em cena. Logo, não nos parece 236 irrelevante que a análise mútua tenha sido empreendida por duas pessoas que, cada uma a seu modo, experimentaram traumas severos na infância. Além disso, é importante notar que a atenção e a teorização mais tardias de Ferenczi a respeito do trauma passaram a incluir uma leitura profundamente crítica ao comportamento dos analistas, que em geral se preocupariam com: "1. Seus próprios confortos. Falta de consideração. Usando [os] analisandos ao invés de permitirem que se desenvolvam" (Ferenczi, 1932/1988, p. 183). O autor ainda acrescenta um segundo ponto:

2. Elementos sádicos e masoquistas permitidos na atmosfera que originalmente era claramente benevolente. Prazer na dor dos outros, porque o próprio sofrimento analítico é recalcado. Eu mesmo oscilei entre sadismo (atividade) e masoquismo (relaxamento). - Ao invés de ser sereno, bem disposto, benevolente:

Sensibilidade do analista (injustificada) (desejo por vingança).

Ênfase excessiva na situação analítica.

(Vaidade) TIRANIA: contra a independência.

Analisandos são crianças. Análise prolongada (mantendo-os crianças ao invés de deixá-los ir). (p. 183)

Vemos nessa passagem como o psicanalista húngaro reconhece sua oscilação entre o que, no limite, torna-se sadismo - um excesso de atividade 


\section{ARTIGOS}

da parte do analista geradora de desprazer, em especial quanto a prescrições sobre o que o paciente pode ou não fazer - e o que, também no limite, torna-se masoquismo - um excesso de relaxamento que finda por submeter o analista aos desejos e anseios do paciente e pode abolir as diferenças entre um e outro. ${ }^{16} \mathrm{~A}$ análise mútua seria exemplo disso. O que se segue a esse reconhecimento é uma listagem de problemas que exemplificam, de maneira não muito clara, as dificuldades contratransferenciais que notou em sua prática: a sensibilidade injustificada do analista, sua identificação com o paciente, para além do "sentir com" (Ferenczi, 1928/2002a), da empatia necessária ao trabalho, pode conduzir a um desejo por vingança; a ênfase na situação analítica (leia-se, em sua caracterização clássica) também leva à oscilação malsã de posições estanques; a vaidade do analista, seu narcisismo, diríamos, ganha a forma de tirania que impede a independência do paciente, ou seja, o fim da análise. Por fim, temos a frase sobre os analisandos serem crianças, que parece ignorar uma observação que o próprio autor fizera quando do início da análise mútua, numa entrada de seu Diário datada de 13 de março de 1932:

Certas fases da análise mútua representam a completa renúncia a toda compulsão e a toda autoridade dos dois lados: elas dão a impressão de duas crianças igualmente aterrorizadas que comparam suas experiências e, devido a seu destino comum, compreendem uma a outra completamente e instintivamente tentam se confortar. (Ferenczi, 1932/1988, p. 56)

Há a criança no adulto em análise, e há a criança no analista. Se, em alguns momentos, a eliminação da (ou a alteração na) assimetria entre paciente e analista pode ser benéfica, em outras condições pode gerar certas problemáticas. Seus benefícios ancoram-se na possibilidade de propiciar, por exemplo, o "entrar em um jogo" (Ferenczi, 1931/2002c, p. 129) — a criação de um espaço potencial - que permite o aprofundamento da análise e abre novos caminhos para a comunicação, a repetição e a elaboração de situações

\footnotetext{
${ }^{16}$ Argumentos nesse sentido levaram Ferenczi (1928/2002a) ao contra-argumento: "Não devo surpreender-me se um dia ouvir minhas visões sobre a paciência requerida do analista usadas para justificar uma técnica masoquista. De todo modo, o método que sigo e recomendo - o da elasticidade da técnica — não é equivalente à não resistência e rendição. Verdade, tentamos seguir o paciente em todos seus humores, mas nunca deixamos de nos mantermos firmes ao ponto de vista que nos é ditado por nossa experiência psicanalítica" (p. 100). O contra-argumento aos extremos nessa técnica, como vemos, termina sendo emitido pelo próprio Ferenczi.
} 
traumáticas. Essa experiência, parece-nos, pode ser mais extrema do que aquilo que Ferenczi (1928/2002a) quer dizer ao usar o termo Einfühlung, "sentir com", e que Kupermann (2019), a partir de uma indicação de Chaim Katz, preferiu traduzir por "sentir dentro" (p. 109). O que encontramos no "caso Ferenczi", na análise mútua e na clínica de outros psicanalistas contemporâneos, que não realizam análises mútuas, são experiências maiores ou mais discretas de colapso (breakdown) dos analistas dentro das análises: de um "enlouquecer com". Trata-se de um sair temporariamente do próprio eixo, num movimento intrínseco de não normatização, que ora se revela como abertura à alteridade radical, transformadora e potencialmente enlouquecedora do outro, ora como um mergulho na própria "doidice reprimida" (Figueiredo, 2019, p. 178), ou na cota de loucura "privada" (Green, 1990). Nessas situações extremas, não se "sente com", e também não se "sente dentro", mas se enlouquece com ou na companhia do paciente, fazendo do colapso temporário e delimitado do próprio psiquismo, e de suas defesas, um material potencialmente mobilizador para a análise.

No entanto, não resta dúvida de que o benefício está fadado a transformar-se em problema caso o analista não se dê conta de que a necessidade 238 de regredir com o paciente em determinadas situações — de "sentir com" (Ferenczi, 1928/2002a), ou mesmo de "enlouquecer com" ele — envolve, como condição sine qua non para a confiança de alguns pacientes e para o trabalho terapêutico, que o analista também tenha a capacidade de eventualmente sair do estado regressivo, enlouquecido, e pensar sobre o que ocorreu ou está ocorrendo na sessão. Dito de outra forma, uma das duas crianças aterrorizadas deve conservar a percepção de que a elasticidade identificatória (Dal Molin, 2018) a que se permitiu, para acompanhar o paciente no que podem ser as trevas da realidade psíquica, demanda o retorno a uma atitude autorreflexiva, de natureza confiável, reservada e, se for o caso, analítica.

Retomando brevemente nosso trajeto, parece-nos que o "caso Ferenczi", nos termos em que pôde ser identificado na obra de Elizabeth Severn (2017), levanta três questões à psicanálise contemporânea: uma reavaliação da ênfase diagnóstica (útil, é verdade, mas muitas vezes excessivamente normativa e limitadora do trabalho clínico); uma reconsideração da realidade clínica enquanto espaço aberto e potencial; e uma nova colocação para o problema da emergência do que é reprimido, fragmentado, louco mesmo, nos analistas - e como isso pode ser fundamental em algumas situações.

Desde já, esperamos que nesse âmbito, da loucura compartilhada, se possa sempre oferecer boa companhia. 


\section{ARTIGOS}

\section{Referências}

Bion, W. R. (1984). Differentiation of the psychotic from the non-psychotic personalities. In Second Thoughts (pp. 43-64). London, UK: Karnac. (Trabalho original publicado em 1957).

Bonomi, C. (1998). Jones's Allegation of Ferenczi's Mental Deterioration: A Reassessment. Int. Forum Psychoanal., 7(4): 201-206.

Bonomi, C. (2018). The Cut and the Building of Psychoanalysis. Volume 2. Sigmund Freud and Sándor Ferenczi. London, UK: Routledge.

Brabant, E., Falzeder, E., \& Giampieri-Deutsch, P. (Eds.) (1993). The Correspondence of Sigmund Freud and Sándor Ferenczi (Vol. 1). Cambridge/London, UK: The Belknap Press of Harvard University Press.

Coelho Junior, N. E. (1995). A força da realidade na clínica freudiana. São Paulo, SP: Escuta.

Coelho Junior, N. E. (2004). Ferenczi e a experiência da Einfühlung. Ágora, 7(1), 73-85.

Coelho Junior, N. E. (2015). Figuras da terceiridade na psicanálise contemporânea: suas origens e seus destinos. Cadernos de Psicanálise, 37(32), 175-195.

Dal Molin, E. C. (2016). O terceiro tempo do trauma: Freud, Ferenczi e o desenho de um conceito. São Paulo, SP: Perspectiva.

Dal Molin, E. C. (2017). Trauma, silêncio e comunicação. In C. P. França (Org.), Ecos do silêncio: reverberações do traumatismo sexual (p. 63-86). São Paulo, SP: Blucher.

Dal Molin, E. C. (2018). O caderno de Wassily: um estudo sobre a violência na clínica psicanalítica. Tese de Doutorado, Instituto de Psicologia, Universidade de São Paulo, São Paulo. doi:10.11606/T.47.2018.tde-04092018-170241.

Dal Molin, E. C. (2019). “'Enlouquecer com': o caso Ferenczi”. Proposta de roda de conversa apresentada no II Encontro do Grupo Brasileiro de Pesquisas Sándor Ferenczi - "Ferenczi: a clínica nos confins". PUC-Rio, Rio de Janeiro, 1 e 2 de novembro de 2019.

Dal Molin, E., Coelho Junior, N., \& Cromberg, R. (2019). A pulsão de morte no primeiro Ferenczi: quietude, regressão e os primórdios da vida psíquica. Estilos da Clínica, 24(2), 231-245.

Federn, P. (1953). Ego Psychology and the Psychoses. London, UK: Imago.

Ferenczi, S. (1988). The Clinical Diary of Sándor Ferenczi (J. Dupont, Ed.). Cambridge: Harvard University Press. (Trabalho original publicado em 1932).

Ferenczi, S. (2002a). The elasticity of psycho-analitic technique. In M. Balint (Ed.), Final Contributions to the Problems and Methods of Psycho-analysis (pp. 87-101). London, UK: Karnac. (Trabalho original publicado em 1928). 
Ferenczi, S. (2002b). The Principle of Relaxation and Neocatharsis. In M. Balint (Ed.), Final Contributions to the Problems and Methods of Psycho-Analysis (pp. p.108-125). London, UK: Karnac. (Trabalho original publicado em 1930).

Ferenczi, S. (2002c). Child analysis in the analysis of adults. In M. Balint (Ed.), Final Contributions to the Problems and Methods of Psycho-analysis (pp. 126-142). London, UK: Karnac. (Trabalho original publicado em 1931).

Ferenczi, S. (2002d). Confusion of tongues between adults and the child: The language of tenderness and of passion. In M. Balint (Ed.), Final Contributions to the Problems and Methods of Psycho-analysis (pp. 156-167). London, UK: Karnac. (Trabalho original publicado em 1933).

Ferenczi, S. (2011). Transferência e introjeção. In Psicanálise I (2ª ed., pp. 87-123), São Paulo, SP: Martins Fontes. (Trabalho original publicado em 1909).

Figueiredo, L. C. (2019). Ser psicanalista: um ofício meio doido. Estudos de Psicanálise, 52, 173-180.

Fortune, C. (1993). The case of 'RN': Sándor Ferenczi's radical experimente in psychoanalysis. In L. Aron, A. Harris (Eds.), The Legacy of Sándor Ferenczi (pp. 101-120). Hillsdale, NJ: Analytic Press.

Fortune, C. (1996). Mutual analysis: a logical outcome of Sándor Ferenczi's experiments in psychoanalysis. In P. L. Rudnytsky, A. Bokay, and P. Giampieri-Deutsch (Eds.), Ferenczi's Turn in Psychoanalysis (pp. 170-186). New York, NY: New York University Press.

Freud, S. (1977). Psicopatologia da vida cotidiana. In Edição Standard Brasileira das Obras Psicológicas Completas de Sigmund Freud (vol. VI; pp.234-245). Rio de Janeiro, RJ: Imago. (Trabalho original publicado em 1901).

Freud, S. (2019). Análise terminável e interminável. In Obras Completas de Sigmund Freud (Vol. XIX). São Paulo, SP: Companhia das Letras. (Trabalho original publicado em 1937).

Green, A. (1990). La folie privée. Paris, FR: Gallimard.

Gondar, J. (2017). Trauma, monismo e pulsão de morte. Conferência apresentada no II Colóquio do Núcleo de Estudos em Psicanálise e Clínica da Contemporaneidade (NEPECC). IPUB/UFRJ, Rio de Janeiro, 4 de agosto de 2017.

Gondar, J. (2019). Ferenczi, crítico da normatividade. Conferência apresentada no II Encontro do Grupo Brasileiro de Pesquisas Sándor Ferenczi - "Ferenczi: a clínica nos confins". PUC-Rio, Rio de Janeiro, 1 e 2 de novembro de 2019.

Kahtuni, H., \& Sanches, G. (2009). Dicionário do pensamento de Sándor Ferenczi - Uma contribuição à clínica psicanalítica contemporânea. Rio de Janeiro, RJ: Elsevier.

Knobloch, F. (2019). A ruptura como eficácia traumática. Conferência apresentada no 


\section{ARTIGOS}

I Encontro do Grupo Brasileiro de Pesquisas Sándor Ferenczi - "Soltar as línguas na Psicanálise". USP e PUC-SP, São Paulo, 7 e 8 de junho de 2019.

Kupermann, D. (2019). Por que Ferenczi? São Paulo, SP: Zagodoni.

Loewald, H. (1980). Ego and Reality. In H. Loewald (Ed.), Papers on Psychoanalysis (pp. 3-20). New Haven and London: Yale University Press. (Trabalho original publicado em 1951).

Mello, R. M., Féres-Carneiro, T., \& Magalhães, A. S. (2019). Trauma, clivagem e progressão intelectual: um estudo sobre o bebê sábio ferencziano. Psicologia em Estudo, 24, on-line.

Mezan, R. (2014). O tronco e os ramos. São Paulo, SP: Companhia das Letras.

Rachman, A. W. (2018). Elizabeth Severn. The "Evil Genius" of Psychoanalysis. New York and London: Routledge.

Rudnytsky, P. L. (2017). Introduction: The other side of the story: Severn on Ferenczi and mutual analysis. In P. L., Rudnytsky (Ed.), The Discovery of the Self: A Study in Psychological Cure (pp. 1-20). London, UK: Routledge.

Sabourin, P. (1988). Ferenczi: paladino e grão-vizir secreto. São Paulo, SP: Martins Fontes.

Severn, E. (2017). The Discovery of the Self: A Study in Psychological Cure. London, UK: Routledge.

Sigal, A. M. (2018). O que a psicanálise tem a dizer sobre o chamado Transtorno de Déficit de Atenção Com ou Sem Hiperatividade, ADD ou ADHD. Percurso: Revista de Psicanálise, 61, on-line.

Verztman, J. S. (2002). O observador do mundo: a noção de clivagem em Ferenczi. Ágora: Estudos em Teoria Psicanalítica, 5(1), 59-78. https://dx.doi. org/10.1590/S1516-14982002000100005.

Winnicott, D. W. (2007). Playing and reality ( $2^{\mathrm{a}}$ ed.). London, UK: Routledge. (Trabalho original publicado em 1971).

\section{Resumos}

("To go crazy with": Ferenczi's case and some questions for contemporary psychoanalysis)

Based on the "Ferenczi case", as identified in a text by his patient/analyst, Elizabeth Severn, this article presents and discusses three issues of contemporary psychoanalysis: a critique of the emphasis on diagnostic interpretation, especially when it is standardizing, the creation of intersubjective spaces in analysis and their potential dimension and the way that "madness", once shared, psychically mobilizes 
and allows relevant content to emerge in both the patient and the analyst. This article further discusses whether the possibility of adopting a non-normative position towards disruptive elements of the other's psyche could be the result, at least in part, of the analyst's ability to move between the fragments of his own psyche.

Key words: Ferenczi, Severn, psychoanalysis, madness, countertransference

(«Deviens fou avec»: le cas Ferenczi et quelques questions pour la psychanalyse contrermporaine

Basé sur le «cas Ferenczi», tel qu'identifié dans un texte de sa patientel analyste, Elizabeth Severn, l'article présente et développe trois enjeux pertinents à la psychanalyse contemporaine: une critique de l'accent mis sur la lecture diagnostique, surtout lorsqu'elle est normative, la création d'espaces intersubjectifs lors de l'analyse et leur dimension potentielle et la manière dont la «folie», une fois partagée, se mobilise psychiquement et permet l'émergence de contenus pertinents tant pour le patient que pour l'analyste. On discute si la possibilité d'adopter une position non normative face aux éléments perturbateurs de la psyché de l'autre ne serait pas, au moins en partie, le résultat de la capacité de l'analyste à se déplacer entre des fragments de sa propre psyché.

Mots-clés: Ferenczi, Severn, psychanalyse, folie, contre-transfert

("Volverse loco": el caso Ferenczi y algunas preguntas para el psicoanálisis contemporáneo)

Basado en el "caso Ferenczi”, según lo identificado en un texto de su paciente/analista, Elizabeth Severn, el articulo presenta y desarrolla tres cuestiones pertinentes al psicoanálisis contemporáneo: una crítica al énfasis en la lectura diagnóstica, especialmente cuando es normativa; la creación de espacios intersubjetivos en el análisis y su dimensión potencial; y la forma en la que la “locura”, una vez compartida, se moviliza psíquicamente y permite la aparición de contenido relevante tanto para el paciente como para el analista. Se discute si la posibilidad de adoptar una posición no normativa frente a los elementos disruptivos de la psique del otro no sería, al menos en parte, el resultado de la capacidad del analista para moverse entre fragmentos de su propia psique.

Palabras clave: Ferenczi, Severn, psicoanálisis, locura, contratransferencia

Citação/Citation: Dal Molin, E. C., Klein, T., Dal Molin, I. S. B., Coelho Junior, N. E. (2020, junho). "Enlouquecer com": o caso Ferenczi e algumas questões para a psicanálise contemporânea. Revista Latinoamericana de Psicopatologia Fundamental, 23(2), 221-244. http://dx.doi.org/10.1590/1415-4714.2020v23n2p221.5. 


\section{ARTIGOS}

Editora/Editor: Prof. Dr. Júlio Verztman

Submetido/Submitted: 14.3.2020/3.14.2020 Aceito/Acepted: $17.5 .2020 / 5.17 .2020$

Copyright: (C) 2009 Associação Universitária de Pesquisa em Psicopatologia Fundamental/ University Association for Research in Fundamental Psychopathology. Este é um artigo de livre acesso, que permite uso irrestrito, distribuição e reprodução em qualquer meio, desde que o autor e a fonte sejam citados / This is an open-access article, which permits unrestricted use, distribution, and reproduction in any medium, provided the original authors and sources are credited.

Financiamento/Funding: Este trabalho não recebeu apoio / This work received no funding.

Conflito de interesses/Conflict of interest: Os autores declaram que não há conflito de interesses. / The authors declare that there is no conflict of interest.

Eugênio Canesin Dal Molin

Doutor pelo Instituto de Psicologia da Universidade de São Paulo - USP (São Paulo, SP, Br); Membro de Depto. de Psicanálise do Instituto Sedes Sapientiae (São Paulo, SP, Br) e membro fundador do Grupo Brasileiro de Pesquisas Sándor Ferenczi; Professor do Centro Universitário Filadélfia - Unifil (Londrina, PR, Br).

Rua Oscar Freire, 1513/92

05409-001 São Paulo, SP, Br

eecdm@yahoo.com.br

https://orcid.org/0000-0002-7360-0969

\section{THAIS KLEIN}

Doutora em Teoria Psicanalítica pelo Programa de Pós-Graduação em Teoria Psicanalítica da Universidade Federal do Rio de Janeiro - UFRJ (Rio de Janeiro, RJ, Br); Doutora em Saúde Coletiva pelo Instituto de Medicina social da Universidade Estadual do Rio de Janeiro - UERJ (Rio de Janeiro, RJ, Br); Professora auxiliar do Centro Universitário Augusto Motta (Rio de Janeiro, RJ, Br); Membro do Grupo Brasileiro de Pesquisas Sandor Ferenczi e do Núcleo de Estudos em Psicanálise e Clínica da Contemporaneidade (NEPECC-IPUB-UFRJ).

Rua Tonelero, 162/4 - Copacabana

22030-002 Rio de Janeiro, RJ, Br

thaiskda@gmail.com

https://orcid.org/0000-0002-5050-9855 
Isabella Silva Borghesi Dal Molin

Especialista em Teoria Psicanalítica pela Pontifícia Universidade Católica de São Paulo - PUC-SP (São Paulo, SP, Br); Aspirante a membro do Depto. de Psicanálise do Instituto Sedes Sapientiae (São Paulo, SP, Br); Membro do Grupo Brasileiro de Pesquisas Sándor Ferenczi; Professora do Centro Universitário Filadélfia - Unifil, (Londrina, PR, Br).

Avenida Harry Prochet, 550/3A 86047-040 Londrina, PR, Br. isborghesi@hotmail.com https://orcid.org/0000-0002-4635-7510

\section{Nelson Ernesto Coelho Junior}

Professor-doutor do Instituto de Psicologia da Universidade de São Paulo - USP (São Paulo, SP, Br).

Alameda Lorena, 1359/52

01424-001 São Paulo, SP, Br

ncoelho@usp.br

https://orcid.org/0000-0002-0707-7356

This is an open-access article, which permits unrestricted use, distribution, the original authors and sources are credited. 